\title{
Juxtaglomerular apparatus T-cell infiltration affects glomerular structure in Type 1 diabetic patients
}

\author{
R. Moriya ${ }^{1}$, J. C. Manivel ${ }^{2}$, M. Mauer ${ }^{2,3}$, for the International Diabetic Nephropathy Study Group (IDNSG) \\ ${ }^{1}$ Kitasato University School of Medicine, Kitasato Sagamihara, Japan \\ 2 University of Minnesota, USA \\ ${ }^{3}$ MMC 491, 420 Delaware Street S.E., Minneapolis, USA
}

\section{Abstract}

Aims/hypothesis. Type 1 diabetes is an autoimmune disorder associated with T-cell mediated injury to multiple endocrine tissues. T-cell infiltration of the juxtaglomerular apparatus could be associated with changes in local renin angiotensin system activity and, thus, with changes in the renal microenvironment. We examined the frequency of juxtaglomerular apparatus T-cell infiltration early in Type 1 diabetes and tested whether this is associated with renal structure and function.

Methods. We classified 89 Type 1 diabetic patients by immunohistochemical analysis as either juxtaglomerular apparatus T-cell positive $(n=37)$ or T-cell negative $(n=38)$. Borderline cases $(n=14)$ were not considered further.

Results. T-cell positive patients had a shorter duration of diabetes $(6.7 \pm 2.5$ years $)$ than $\mathrm{T}$-cell negative pa- tients $(9.2 \pm 5.0$ years, $p=0.011)$ and lower albumin excretion rate, but they had a similar glomerular filtration rate and blood pressure. Renal biopsy morphometric analysis showed similar glomerular basement membrane width and mesangial fractional volume in these two groups. However, glomerular capillary surface density $(p=0.0012)$ and filtration surface per glomerulus ( $p=0.0155$ ) were greater in the T-cell positive patients.

Conclusion/Interpretation. Increased filtration surface per glomerulus could be associated with glomerular filtration rate preservation in diabetes. Thus, juxtaglomerular apparatus immunologic injury in Type 1 diabetes patients could delay the clinical consequences of diabetic nephropathy. [Diabetologia (2004) 47:82-88]

Keywords Diabetic nephropathy - Type 1 diabetes . juxtaglomerular apparatus $\cdot$ T-cell
Received: 7 April 2003 / Revised: 11 August 2003

Published online: 15 November 2003

C) Springer-Verlag 2003

M. Mauer ( $)$, MMC 491, 420 Delaware Street S.E., Minneapolis, MN 55455, USA

E-mail:mauer002@umn.edu

Abbreviations: ECM, Extracellular matrix; RAS, renin-angiotensin-system; JGA, juxtaglomerular apparatus; NHDN, natural history of diabetic nephropathy; IP, immunoperoxidase; GV, mean glomerular volume; TGF-B, transforming growth factor$\mathrm{B} ; \mathrm{Vv}(\mathrm{Mes} / \mathrm{glom})$, mesangial fractional volume per glomerulus; GBM, glomerular basement membrane; Sv(PGBM/glom), surface density of the peripheral glomerular capillary perglomerulus ; TFS, total filtration surface per glomerulus; Vv(Int/cortex), fractional volume of renal cortical interstitium.

See the Acknowledgements for the list of investigators of the International Diabetic Nephropathy Study Group (IDNSG)
Only a subset of Type 1 insulin-dependent diabetic patients develop overt diabetic nephropathy [1]. It is well known that hyperglycaemia is a major risk factor for diabetic nephropathy but hyperglycaemia does not account for all changes observed [2]. Extracellular matrix (ECM) accumulation is central to the glomerular and interstitial lesions that ultimately culminate in diabetic nephropathy $[3,4]$ and studies have suggested that the renin-angiotensin-system (RAS) has an important influence on renal ECM dynamics [4]. Glucose could increase mesangial cell angiotensin II production [5]. Angiotensin II upregulates TGF- $\beta$ receptor expression in cultured mesangial cells, thus stimulating ECM production [6]. Angiotensin II inhibits mesangial cell collagenase activity [7] and these effects can be blocked by Losartan [7], an angiotensin II receptor blocker. Angiotensin converting enzyme in- 
hibitors reduce fibronectin [8] and matrix metalloproteinase [9] production of mesangial cells exposed to high glucose.

TGF- $\beta$, an important regulator of ECM production and turnover, is expressed in the human kidney in the hypertrophic juxtaglomerular apparatus (JGA) in parallel with renin [10]. Increased prorenin and total plasma renin accompany and can even precede increases in urinary albumin excretion rate $[11,12]$, a marker for the development of serious underlying diabetic nephropathy lesions [13]. Because TGF- $\beta$ and renin and/or prorenin could be linked through their production and release from the JGA and because both have been related to diabetic renal disease, it would seem that the JGA could be an etiologically related to the development of diabetic nephropathy.

A number of structural changes in the JGA have been described in diabetes. The contact area between the macula densa and the Goormaghtigh cells of the JGA is increased by $38 \%$ in rats after 50 days of diabetes, although this duration of diabetes is insufficient for significant diabetic glomerular lesions to develop [14]. A reduced JGA cell count has been reported in 15 autopsy cases with diabetic nephropathy [15]. Enlarged JGA and a positive correlation between JGA size and afferent arteriolar hyalinosis have been found in diabetic patients with glomerulosclerosis [16]. Increased JGA size and cell number were found in some young Type 1 diabetic patients in contrast to sclerotic JGAs with decreased cell number in others [17]. These lesions were associated with T-lymphocyte infiltration into the JGA in some patients [17]. This latter finding could be of particular relevance since autoimmunity causing Type 1 diabetes may be part of a polyendocrine disorder [18]. Thus, T-lymphocyte infiltration into the JGA could destroy renin-producing cells by pathogenetic mechanisms analogous to pancreatic islet beta-cell destruction. This study explores the relationship between JGA T-lymphocyte infiltration and renal functional and structural changes in a population of young patients with Type 1 (insulindependent) diabetes participating in a diabetic nephropathy natural history study.

\section{Subjects and methods}

Patients. The cohort for this study came from the International Diabetic Nephropathy Study Group, an international study of the natural history of diabetic nephropathy (NHDN) in young Type 1 diabetic patients $[19,20]$. The baseline clinical characteristics, renal function and renal structure data have been detailed elsewhere $[19,20]$. Centers participating in this study included McGill University, Montreal, University of Minnesota, Minneapolis and Hôpital Robert Debré, Hôpital St. Louis, and Hôpital Necker Enfants Malades, Unité Inserm U423, Paris. A total of 243 patients (97\% Caucasian) between 10 to 30 years of age with 2 to 20 years of Type 1 diabetes whose AER was less than $100 \mu \mathrm{g} / \mathrm{min}$ and who had normal GFR and normal BP
Table 1. Number of NHDN* patients with and without JGA Tcell infiltration

Tissues with at least seven glomeruli or four JGAs for analysis

JGA T-cell infiltration positive patients $\quad 37 \quad 41.6 \%$

JGA T-cell infiltration negative patients $\quad 38 \quad 42.7 \%$

Patients borderline for T-cell infiltration $\quad 14 \quad 15.7 \%$

$89 \quad 100 \%$

Tissues with fewer than seven glomeruli or four JGA for analysis

JGA T-cell infiltration positive patients $\quad 6 \quad 8.3 \%$

JGA T-cell infiltration negative patients $\quad 55 \quad 76.4 \%$

Patients borderline for T-cell infiltration $\quad 11 \quad 15.3 \%$

Tissues without glomeruli for analysis $\quad 15$

Total

176

NHDN, Natural history of diabetic nephropathy; JGA, juxtaglomerular apparatus

and no antihypertensive medications at entry were eligible for the NHDN Study. All patients or parents of patients less than 18 years of age gave their informed consent prior to biopsy. This study was approved by the Committees for the use of Human Subjects in Research at each of the participating institutions.

Selection criteria for this study. In preliminary studies, we found a high frequency of false negative results for JGA T-cell infiltration if tissues with small numbers of glomeruli were included. With less than seven glomeruli or four JGAs in a biopsy only $8.3 \%$ of the patients were positive for T-cell infiltration compared to $41.6 \%$ when tissues with at least seven glomeruli or four JGAs were studied (Table 1). Thus, to reduce the risk of false negative results, we used only tissues containing at least seven glomeruli and four JGA areas. Of the 243 NHDN patients that had unstained light microscopy slides available 176 were screened for this study, of whom 89 had adequate numbers of glomeruli or JGA for inclusion. Fourteen of these patients had unclassifiable (borderline) readings for JGA T-cell infiltration (Table 1) and were not included, leaving 75 patients in this cohort. There were no statistically significant differences in age, age at onset, duration, sex, $\mathrm{HbA}_{1 \mathrm{c}}, \mathrm{AER}, \mathrm{BP}$ or renal morphometry between this cohort and the other 168 patients in this study. The control subjects were 17 normal kidney donors (16 cadaveric) who were matched for age and sex to the diabetic patients and who underwent a lower pole needle donor kidney renal biopsy at the time of renal transplant surgery.

Clinical studies. Baseline clinical data were obtained at the time of renal biopsy and during the first year of the study. Blood pressure was measured at baseline and quarterly using a Dinamap Vital Signs Monitor, and the mean of the first year's values were used [19]. AER was measured as described previously using the mean of baseline and the first year's quarterly value [19]. Normoalbuminuria was defined as an AER of less than $20 \mu \mathrm{g} / \mathrm{min}$ and microalbuminuria 20 as $20-200 \mu \mathrm{g} / \mathrm{min}$ on at least two of three consecutive measurements. $\mathrm{HbA}_{1 \mathrm{c}}$ was used to assess glycaemic control which is presented as the mean of the baseline and the first year's quarterly values [19]. Glomerular filtration rate was measured using constant infusion methods and timed urine and serum collections as detailed previously [19]. 
Renal biopsy studies: Immunoperoxidase (IP) studies. Renal tissues were obtained by percutaneous biopsy and processed for light microscopy in Zenker's or Brazil solution and embedded in paraffin and electron microscopy fixed in $2.5 \%$ glutaraldehyde in Millonig's buffer as described [20].

Immunoperoxidase light microscopy studies were carried out as follows: paraffin embedded sections were heat dried for $60 \mathrm{~min}$ in a $56^{\circ} \mathrm{C}$ oven before staining. After drying, the slides were deparaffinized through a graded Americlear (Baxter, USA) and alcohol series. Slides were exposed to absolute methanol with $0.6 \%$ hydrogen peroxide to block endogenous peroxidase activity and were rehydrated and then washed in phosphate buffered saline. The primary antisera (Monoclonal Mouse Anti-Human T cell, CD45RO, UCHL-1, Dako, Carpinteria, Calif., USA) was incubated with the tissue overnight at $4^{\circ} \mathrm{C}$ [21]. Detection of the primary antibody was obtained on the second day by using the Vectastain ABC (avidin-biotin complex) system (Vectastain ABC Elite Kit Mouse IgG, Vector, USA), an indirect antibody procedure. Positive reactivity was made visible by development with a chromogen. Haematoxylin was used as a counterstain before the slides were dehydrated and coverslipped. A known positive control was run to rule out primary antiserum problems. Negative controls without the primary antibody were used to detect nonspecific staining.

The evaluation of the slides was done by two of the investigators who were unaware of the patients' identities. Positive slides were defined by the presence of at least two but usually three or more positive staining cells per JGA area (Fig. 1a) in at least $60 \%$ of the JGA areas. Slides were defined as negative if no positive cells were observed in the JGA areas on the slide (Fig. 1b), or if only one positive cell was observed in an occasional JGA $(<25 \%$ JGA). Slides with intermediate amounts of staining were considered as borderline. This classification was developed before any blinded viewing or analyses. The appearance of the JGAs from normal controls or from slides stained without the primary antibody was as illustrated in Fig. 1b.

Renal biopsy studies: morphometric analysis. Sections of $1 \mu \mathrm{m}$ were stained to select the centermost, nonsclerotic glomerulus in the electron microscopy block $[13,19]$ for ultrathin sectioning and processing for morphometric measures. All tissues were masked. Using published and validated morphometric methods, GBM width was measured using the orthogonal intercept method [13, 19]. Mesangial fractional volume per glomerulus $[\mathrm{Vv}(\mathrm{Mes} / \mathrm{glom})]$ was measured by point counting [19]. Surface density of the peripheral glomerular capillary $[\mathrm{Sv}(\mathrm{PGBM} / \mathrm{glom})]$ was estimated on these montages using an intercept counting technique and the epithelial side of the peripheral GBM as the surface to be estimated [13, 19]. Surface density was calculated as:

$S v(P G B M /$ glom $)=2 \times I\left(C P_{G} \times 60,000 / M a g\right)$

where $\mathrm{I}$ is the number of intercepts of a grid line with the peripheral GBM. $\mathrm{CP}_{\mathrm{G}}$ is the number of coarse points hitting a glomerulus. The length in micrometers of the grid line represented by each coarse point is 60,000, and Mag is the magnification of the montage. An average of 218 (range 85-387) intercepts per biopsy was counted in the NHDN study.

Total surface per glomerulus of the peripheral GBM (TFS) was calculated as:

$T F S=S v(P G B M /$ glom $) \times$ GlomVol in $\mu m^{3} \times 10^{3}$

Light microscopy tissues were stained with periodic acid-schiff [19].

Mean glomerular volume (GV) was measured using a projecting microscope at a magnification of $150 \times$ using the Cava-
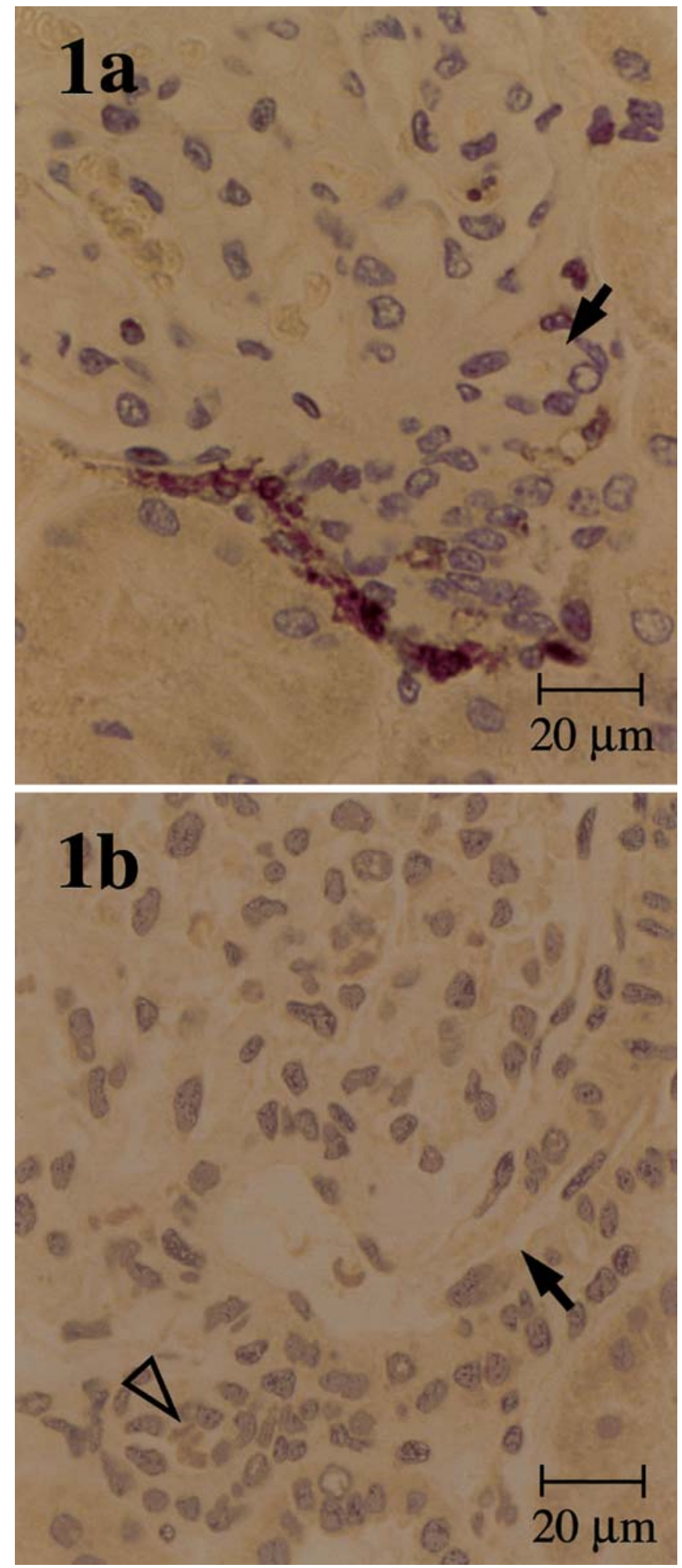

Fig. 1a, b. Glomerulus from (a) Type 1 diabetic patient with positive JGA $\mathrm{T}$ cell staining (peroxidase brown reaction product). Arrow points to a glomerular arteriole.(b) Glomerulus from a Type 1 diabetic patient with negative JGA T-cell staining. Solid arrow points to the afferent glomerular arteriole; outlined arrow points at the efferent glomerular arteriole 
Table 2. Clinical characteristics of NHDN patients with and without JGA T-cell infiltration

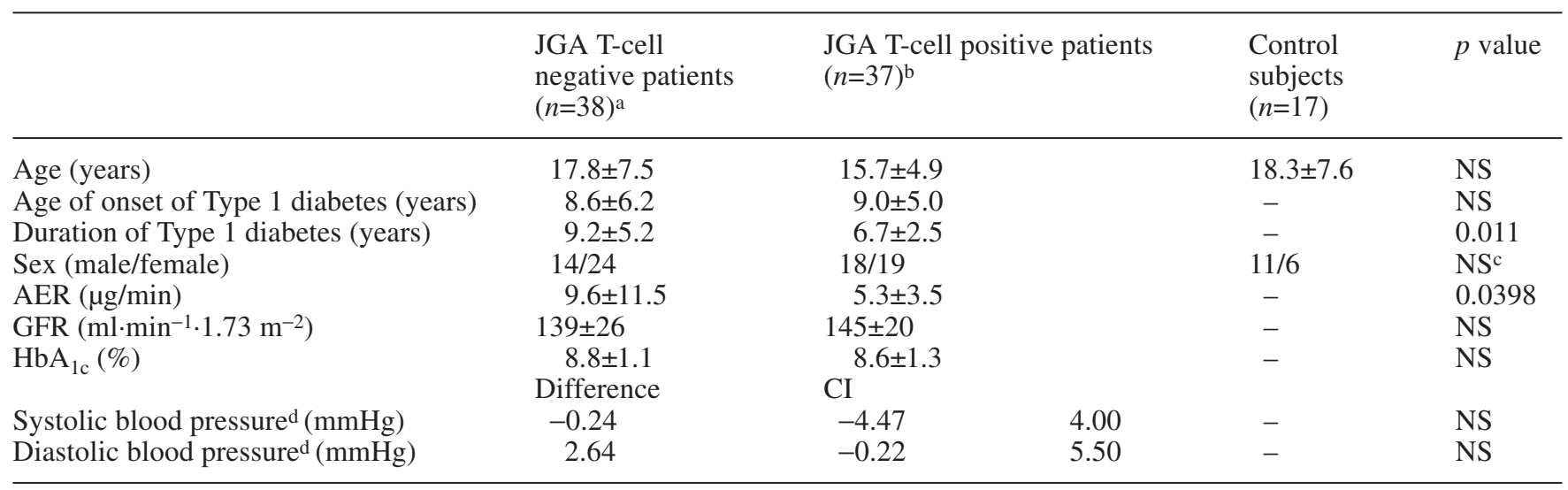

Data are means \pm SD for unadjusted data or mean difference between the groups (confidence interval) for adjusted data NHDN, natural history of diabetic nephropathy; JGA, juxtaglomerular apparatus

lieri method which is independent of glomerular size or shape $[20,22]$. Serial sections obtained at $20 \mu \mathrm{m}$ intervals were examined and glomerular profiles were mapped and numbered. "New" glomeruli, i.e., the ones not seen in the preceding section were identified and area of their profiles in the initial and subsequent sections were estimated by point counting. At least ten glomeruli per kidney specimen were used for GV. Only five controls had sufficient numbers of glomeruli to estimate this parameter. GV (in $\mu \mathrm{m} 3$ ) was calculated using the equation:

$$
G V=20 \times \sum P g \times(5000 / 150)^{2} \times 10^{6}
$$

where 20 is the interval in $\mu \mathrm{m}$ between each fourth section, $\Sigma$ Pg is the sum of grid points hitting all profiles from a glomerulus, 5000 is the distance in $\mu \mathrm{m}$ between grid points, and 150 is the magnification.

The fractional volume of renal cortical interstitium [ $\mathrm{Vv}(\mathrm{Int} / \mathrm{cortex})]$ was measured in projected light microscopy slides by point counting as previously detailed [23].

Statistics. Data are expressed as means \pm SD. Comparisons between groups were done by unpaired Student's $t$ test. Analysis of variance (ANOVA) was used to adjust for age and duration. A chi-square analysis was used for categorical data. A $p$ value of less than 0.05 was considered statistically significant.

\section{Results}

Clinical data. Of the Type 1 diabetic patients 37 $(42 \%)$ were JGA T-cell positive and $38(43 \%)$ were JGA T-cell negative. All control subjects were negative. Age and sex distributions of all three groups were similar and age of onset of Type 1 diabetes was similar in the diabetic patients with and without T-cell infiltration (Table 2). However, the T-cell positive group had a shorter duration of Type 1 diabetes than the T-cell negative group $(p<0.011$, Table 2). All 37 patients in the T-cell positive group were normoalbuminuric whereas three of 38 in the T-cell negative group were microalbuminuric. Albumin excretion rate a $n=38$ except for AER, $n=35$; GFR, $n=37$

b $n=37$ except for AER, $n=36$; GFR, $n=36$

c Analyzed by chi-square

d Adjusted for age

was higher in the T-cell negative group. Glomerular filtration rate values were similar in both groups and the mean values for both groups were above the upper limit of normal $\left(130 \mathrm{ml} \cdot \mathrm{min}^{-1} \cdot 1.73 \mathrm{~m}^{-2}\right)$. The $\mathrm{HbA}_{1 \mathrm{c}}$ values were similar in both groups. Blood pressure was within normal limits in both groups and age adjusted diastolic and systolic BP were similar in the two groups (Table 2).

Morphometric data. Since there was a statistically significant difference in duration of Type 1 diabetes between the T-cell positive and T-cell negative diabetic groups, morphometric data are presented both unadjusted and adjusted for age and duration. $\mathrm{Vv}(\mathrm{Mes} / \mathrm{glom})$ was increased over the control subjects only in the T-cell negative group $(p<0.05$, data not shown), but did not statistically differ between the two diabetic groups (Table 3). Glomerular basement membrane width was increased in both groups compared to the control group $(p<0.001$, data not shown), but did not differ statistically between the two groups. $\mathrm{Sv}$ (PGBM/glom) was similar between the T-cell negative group and control group (data not shown). $\mathrm{Sv}$ (PGBM/glom) was increased in the T-cell positive compared to both the control $(p<0.05)$ and the JGA T-cell negative group (Table 3 ). Glomerular volume was statistically significantly greater than normal only in the T-cell positive group, but only five control subjects had adequate tissue for this parameter. Glomerular volume was not statistically significantly different between the two diabetic groups. However, the JGA T-cell positive patients tended to have larger glomerular volume when adjusted for age and duration compared to the JGA T-cell negative group $(p=0.08$, Table 3). Consequently, filtration surface per glomerulus $[\mathrm{Sv}$ (PGBM/glom) $\times$ glomerular volume] was about $50 \%$ greater than the control group only in the T-cell positive group ( $p<0.05$, data not shown) and was in- 
Table 3. Baseline renal structure in NHDN patients with and without JGA T-cell infiltration

\begin{tabular}{|c|c|c|c|c|}
\hline$\frac{}{\text { Vv (Mes/glom) }}$ & $\begin{array}{l}\text { JGA T-cell } \\
\begin{array}{l}\text { negative patients } \\
(n=38)^{\mathrm{a}}\end{array} \\
0.23 \pm 0.07\end{array}$ & \multicolumn{2}{|c|}{ JGA T-cell positive patients $(n=37)^{\mathrm{b}}$} & $\begin{array}{l}p \text { value } \\
\mathrm{NS}\end{array}$ \\
\hline GBM width (nm) & $439 \pm 93$ & $418 \pm 56$ & & NS \\
\hline $\operatorname{Sv}(\mathrm{PGBM} / \mathrm{glom})\left(\mu \mathrm{m}^{2} / \mu \mathrm{m}^{3}\right)$ & $0.13 \pm 0.02$ & $0.15 \pm 0.02$ & & 0.0002 \\
\hline Glomerular volume $\left(\mu \mathrm{m}^{3} \times 10^{6}\right)$ & $1.42 \pm 0.45$ & $1.53 \pm 0.40$ & & NS \\
\hline $\mathrm{Vv}(\mathrm{Int} / \mathrm{cortex})$ & Difference & CI & & \\
\hline Vv $(\text { Mes/glom })^{c}$ & 0.002 & -0.02 & 0.02 & NS \\
\hline GBM width $(\mathrm{nm})^{\mathrm{c}}$ & 2 & -32.5 & 36.5 & NS \\
\hline $\operatorname{Sv}(\mathrm{PGBM} / \mathrm{glom})\left(\mu \mathrm{m}^{2} / \mu \mathrm{m}^{3}\right)^{\mathrm{c}}$ & -0.02 & -0.027 & -0.007 & 0.0012 \\
\hline Glomerular volume $\left(\mu \mathrm{m}^{3} \times 10^{6}\right)^{\mathrm{c}}$ & -0.16 & -0.35 & 0.02 & $0.08(\mathrm{NS})$ \\
\hline
\end{tabular}

Data are means \pm SD for unadjusted data or mean difference between the groups and confidence intervals for adjusted data NHDN, Natural history of diabetic nephropathy; JGA, juxtaglomerular apparatus; Vv (Mes/glom), mesangial fractional volume; GBM, glomerular basement membrane; Sv(PGBM/glom), filtration surface density; $\mathrm{Vv}$ (Int/cortex), cortical interstitial fractional volume

creased by $20 \%$ in the T-cell positive compared to the T-cell negative patients (Table 3$). \mathrm{Vv}(\mathrm{Int} /$ cortex) did not statistically differ in either diabetic group compared to the control group and did not differ between the patient groups (Table 3).

\section{Discussion}

Enlarged JGAs associated with increased JGA cell number as well as small sclerotic JGAs with decreased JGA cell number have recently been reported in young Type 1 diabetic patients [17]. Either abnormality could occur in the presence or absence of mesangial expansion [17]. This study also reported T-cell infiltration into the JGA in $60 \%$ of 20 Type 1 diabetic patients of 18 to 31 years of age, with or without increased urinary albumin concentrations [17]. Although no analysis of the relationship of JGA T-cell infiltration and duration of diabetes was done, the authors interpreted these findings as suggesting that T-cell infiltration into JGA areas initiated JGA hyperplasia, renin hypersecretion and local glomerular changes of diabetes. Destruction of the JGA noted in these studies led to the hypothesis that early JGA dysfunction could spare the kidney from diabetic glomerulopathy [17].

The present study was done to determine whether these prior observations [17] could be confirmed and whether demographic, clinical or renal morphometric differences exist between Type 1 diabetic patients with and without JGA T-cell infiltration. This study was possible because of the large number of renal a $n=38$ except for glomerular volume and filtration surface per glomerulus, $n=36 ; \mathrm{Vv}$ (Int/cortex), $n=37$

b $n=37$ except for glomerular volume and filtration surface per glomerulus, $n=36$

c Adjusted for age and duration

biopsies available from the NHDN study, ranging from young patients with a relatively brief duration of diabetes to older patients with diabetes for as long as 20 years $[19,20]$. The study included two highly polarized groups, one clearly positive and the other clearly negative for JGA T-cell infiltration in renal biopsy tissues containing at least seven glomeruli or four JGA's. All intermediate cases classified as borderline and cases with fewer than seven glomeruli or four JGA's were omitted from further analysis. This could have allowed for group differences to emerge which would have been obscured using less stringent selection criteria. Diabetes duration was the only demographic variable which differed between the JGA T-cell positive and negative patients, being shorter in the positive group. This suggests that JGA T-cell infiltration is a relatively early finding in some Type 1 diabetic patients and, at least in some instances, disappears over time. It seems reasonable to hypothesise, as suggested previously [17], that JGA T-cell infiltration is a component of the autoimmunity of Type 1 diabetes affecting multiple endocrine organs and resulting not only in the destruction of insulin-producing pancreatic beta cells [17], but also injury to thyroid, gastric parietal cells, adrenal and pituitary tissues $[24,25$, $26,27,28]$. The JGA findings are also consistent with the observations that pancreatic islet lymphocytic infiltration is more common in patients with more recent onset of Type 1 diabetes [29]. It is possible that JGA T-cell infiltration causes JGA-cell dysfunction and leads to destruction of JGA cells and ultimately to the JGA sclerosis that has been noted by others [15]. 
All of the JGA T-cell positive patients and all but three of 38 JGA T-cell negative patients were normoalbuminuric. Moreover, these patients were relatively young and had a relatively short duration of diabetes. Nonetheless, consistent with our previous reports $[13,20]$, glomerular structure was abnormal in both groups, although $\mathrm{Vv}(\mathrm{Mes} / \mathrm{glom})$ did not exceed normal in the JGA T-cell positive group. However, there was no difference in GBM width or $\mathrm{Vv}(\mathrm{Mes} / \mathrm{glom})$ between the two Type 1 diabetic groups.

Interestingly, filtration surface density was increased in the T-cell positive group compared to both T-cell negative Type 1 diabetic patients and normal control subjects. Moreover, glomerular volume was increased in the T-cell positive patients compared to the control subjects and was numerically, although not statistically, greater than in JGA T-cell negative patients. Consequently, filtration surface per glomerulus was more than $50 \%$ above normal in JGA T-cell positive patients and about $20 \%$ greater than in T-cell negative patients even after adjusting for the effects of age and duration. The reason for these changes in glomerular size and architecture in T-cell positive patients is not known, but could be related to local paracrine growth factor or cytokine environmental differences. Clearly, renin is made in this area and TGF- $\beta$ has been found in the JGA co-localizing with renin [10], and, presumably, the T-cells could provide cytokine elaboration. Regardless of the mechanism(s), the structural changes associated with JGA T-cell infiltration could be protective of the glomerulus. Ultimately, loss of filtration surface as a consequence of mesangial expansion is an important mechanism of GFR loss in diabetic nephropathy [30]. Thus, the increased filtration surface in JGA T-cell positive patients could provide a greater safety margin as mesangial expansion occurs [30]. It is possible that this is reflected in the higher AER in the T-cell negative group. Along these lines, glomerular enlargement in Type 1 diabetic patients has been associated with the later development of proteinuria compared to Type 1 diabetic patients with less glomerular enlargement [31]. It is also possible that JGA T-cell positive patients have reduced glomerular exposure to renin angiotensin system activity, and, consequently, less albuminuria [32].

Recent renal functional studies suggest marked variability in the level of RAS activation in Type 1 diabetic patients and posited that failure to activate the intrarenal RAS among some patients was protective for diabetic nephropathy [33]. It is conceivable that T-cell infiltration of the JGA can ultimately lead to reduced JGA endocrine and paracrine function, as is true of parallel phenomena in islet, thyroid and other endocrine tissues in the course of diabetic polyendocrinopathy $[26,27,28,29,30]$, and that this could explain the variability found in response to RAS blockade among Type 1 diabetic patients [33].
In conclusion, JGA T-cell infiltration is common among young Type 1 diabetic patients, especially those with shorter duration of diabetes, and is associated with increased glomerular filtration surface and lower AER. Whether JGA T-cell infiltration will result in JGA structural and functional injury and whether this injury is associated with differences in the risk of the development or progression of diabetic nephropathy could emerge from the 5-year NHDN follow-up studies.

Acknowledgements. This work was primarily supported by grants from the Juvenile Diabetes Foundation International. Clinical studies in Minneapolis were supported by a General Clinical Research Center (GCRC) grant (M01-RR00400) from the National Center for Research Resources and the National Institutes of Health. Support was also provided by the Emma Howe Foundation and the Robert Palmer Fund. Dr. R. Moriya was supported by a Juvenile Diabetes Foundation International (JDFI) Research Fellowship Award. Dr. S. Suissa is the recipient of a Senior Scientist Award from the Medical Research Counsel of Canada. Mr. J. Basgen and Ms. S. Sisson-Ross performed the renal morphometry studies. Ms. S. Kupcho performed the urinary albumin measurements. Ms. J. Bucksa headed the clinical research laboratory. Ms. P. L. Erickson and J. Stein prepared this manuscript. Ms. T. Strand, M. Nolander, P. Moynihan, V. Siefert, and M. Watrin performed the coordinator duties in Minnesota, while B. Maruca assisted in this capacity in Montreal, and C. Delcroix, MD and D. Simon, MD performed the coordinator duties in Paris. Ms. M. Mills coordinated the Montreal laboratory efforts. Ms. H. Beaufils and V. Beaudoin performed many of the clinical studies in Paris. We also thank the nurses at the General Clinical Research Center at Fairview-University Medical Center and at the International Diabetes Center in Minneapolis, and Ms. M. Proulx at St. Paul Children's Hospital for their excellent patient care. We are especially grateful to Ms. R. Meerovici who performed the data cleaning and entry and Ms. S. Dell'Aniello who performed the statistical analyses for these studies.

The International Diabetic Nephropathy Study Group (IDNSG): C. Aebi, M. Belmonte, K. Drummond, R. Gardiner, M. Kramer, D. Laforte, C. Polychronakos, A. Schiffrin, S. Suissa, McGill University, Montreal, Quebec, Canada; K. Khoury, CHU de Sherbrooke, Sherbrooke, Quebec, Canada; J. Braaten, K. Faught, University of Ottawa, Ottawa, Canada; P. Czernichow, Université Paris VII, Paris, France; M.-C. Gubler, Hôpital Necker-Enfants Malades, Paris, France; C. Levy-Marchal, INSERM Unité, Paris, France; P. Passa, Hôpital Saint Louis, Paris, France; R. Carpenter, B. Chavers, Y. Kim, M. Mauer, K. Saxena, A. Sinaiko, J. Sockalosky, M. Spencer, M. Steffes, R. Vernier, University of Minnesota, Minneapolis, Minnesota, USA

\section{References}

1. Anderson AR, Christensen JS, Anderson JK, Kreiner S, Deckert T (1983) Diabetic nephropathy in Type I (insulindependent) diabetes: an epidemiological study. Diabetologia 25:496-501

2. Deckert T, Poulsen JE (1981) Diabetic nephropathy: fault or destiny? Diabetologia 21:178-183

3. Falk RJ, Scheinman JI, Mauer SM, Michael AF (1983). Polyantigenic expansion of basement membrane constituents in diabetic nephropathy. Diabetes 32:34-39 
4. Caramori MLA, Mauer M (2003) Pathophysiology of renal complications. In: Porte D Jr, Sherwin RS, Baron A (eds) Ellenberg \& Rifkin's diabetes mellitus, 6th edn. McGrawHill, New York, pp 697-722

5. Zhang S-L, Filep JG, Hohman TC, Tang S-S, Ingelfinger JR, Chan JSD (1999) Molecular mechanisms of glucose action on angiotensinogen gene expression in rat proximal tubular cells. Kidney Int 55:454-464

6. Border WA, Noble NA (1998) Interactions of transforming growth factor-beta and angiotensin II in fibrosis. Hypertension 31:181-188

7. Singh R, Alavi N, Singh AK, Leehey DJ (1999) Role of angiotensin II in glucose-induced inhibition of mesangial matrix degradation. Diabetes 48:2066-2073

8. Campbell-Boswell M, Robertson AL (1984) Effects of angiotensin II and vasopressin on human smooth muscle cells in vitro. Exp Mol Pathol 26:147-175

9. Sorbi D, Fadly M, Hicks R, Alexander S, Arbeit L (1983) Captopril inhibits the $72 \mathrm{kDa}$ and $92 \mathrm{kDa}$ matrix metalloproteinases. Kidney Int 44:1266-1272

10. Ray PE, McCune BK, Gomez RA, Ruley EJ, Klotman PE (1994) Expression of transforming growth factor $\beta 3$ in hypertrophic juxtaglomerular apparatus. N Engl J Med 330:68-69

11. Wilson DM, Luetscher JA (1990) Plasma prorenin activity and complications in children with insulin-dependent diabetes mellitus. N Engl J Med 323:1101-1106

12. Deinum J, Rønn B, Mathiesen E, Derkx FHM, Hop WCJ, Schalekamp MADH (1999) Increases in serum prorenin precedes onset of microalbuminuria in patients with insulindependent diabetes mellitus. Diabetologia 42:1006-1010

13. Fioretto P, Steffes MW, Mauer M (1994) Glomerular structure in nonproteinuric IDDM patients with various levels of albuminuria. Diabetes 43:1358-1364

14. Rasch R, Holck P (1988) Ultrastructure of the macula densa in streptozotocin diabetic rats. Lab Invest 59:666-672

15. Shindler AM, Sommers SC (1966) Diabetic sclerosis of renal juxtaglomerular apparatus. Lab Invest 15:877-884

16. Bader H, Meyer DS (1977) The size of the juxtaglomerular apparatus in diabetic glomerulosclerosis and its correlation with arteriolosclerosis and arterial hypertension: a morphometric light microscopic study on human renal biopsies. Clin Nephrol 8:308-311

17. Paulsen EP, Burke BA, Vernier RL, Mallare MJ, Innes DJ Jr, Sturgill BC (1994) Juxtaglomerular body abnormalities in youth-onset diabetic subjects. Kidney Int 45:1132-1139

18. Atkinson MA, Maclaren NK (1994) The pathogenesis of insulin-dependent diabetes mellitus. $N$ Engl J Med 331:1428-1436

19. Mauer M, Drummond K, for the International Diabetic Nephropathy Study Group (IDNSG) (2002) The early natural history of nephropathy in type 1 diabetes. I. Study design and baseline characteristics of the study participants. Diabetes 51:1572-1579
20. Drummond K, Mauer M, for the International Diabetic Nephropathy Study Group (IDNSG) (2002) The early natural history of nephropathy in type 1 diabetes. II. Early renal structural changes in type 1 diabetes. Diabetes 51:1580-1587

21. Norton AJ, Ramsay AD, Smith SH, Beverly PC, Isaacson PG (1986) Monoclonal antibody (UCHL-1) that recognizes normal and neoplastic T-cell in routinely fixed tissues. J Clin Pathol 39:399-405

22. Lane PH, Steffes MW, Mauer SM (1992) Estimation of glomerular volume: a comparison of four methods. Kidney Int 41:1085-1089

23. Lane PH, Steffes MW, Fioretto P, Mauer SM (1993) Renal interstitial expansion in insulin-dependent diabetes mellitus. Kidney Int 43:661-667

24. Srikanta S, Malavia AN, Mehra NK, Vaidya MC, Geevarghese PJ, Ahuja MMS (1981) Autoimmunity in type I (insulin dependent) diabetes mellitus in North India. J Clin Immunol 1:169-173

25. Nerup J, Binder C (1973) Thyroid, gastric and autoimmunity in diabtetes mellitus. Acta Endoclinol 172:279286

26. Nagaoka K, Sakurai T, Nabeya N, Imura H, Kuno S (1979) Antimicrosomal antibodies, gastric parietal cell antibodies and antinuclear factors in insulin dependent diabetes mellitus. Endocrinol Jpn 26:599-603

27. Mirakian R, Bottazzo GF, Cudworth AG, Richardson CA, Doniach D (1982) Autoimmunity to anterior pituitary cells and the pathogenesis of insulin-dependent diabetes mellitus. Lancet (i):755-759

28. Schopfer K, Matter L, Tenschert R, Bauer S, Zuppinger K (1982) Anti-glucagon-cell and anti-adrenal medullary-cell antibodies in islet-cell autoantibody-positive diabetic children. N Engl J Med 310:1536-1537

29. Westermark P (2003) Pathology of the Pancreas in Diabetes Mellitus. In: Porte D Jr, Sherwin RS, Baron A (eds) Ellenberg \& Rifkin's diabetes mellitus, 6th edn. McGrawHill, New York, pp 257-263

30. Ellis EN, Steffes MW, Goetz FC, Sutherland DER, Mauer SM (1986) Glomerular filtration surface in type I diabetes mellitus. Kidney Int 29:889-894

31. Bilous RW, Mauer SM, Sutherland DER, Steffes MW (1989) Mean glomerular volume and rate of development of diabetic nephropathy. Diabetes 38:1142-1147

32. Lapinski R, Perico N, Remuzzi A, Sangalli F, Benigni A, Remuzzi G (1996) Angiotensin II modulates glomerular capillary permselectivity in rat isolated perfused kidney. J Am Soc Nephrol 7:653-660

33. Hollenberg NK, Price DA, Fisher NDL et al. (2003) Glomerular hemodynamics and the renin-angiotensin system in patients with type 1 diabetes mellitus. Kidney Int 63:172-178 